\title{
Management of cardiac fibrosis in diabetic rats; the role of peroxisome proliferator activated receptor gamma (PPAR-gamma) and calcium channel blockers (CCBs)
}

\author{
Hoda E Mohamad', Mervat E Askar' and Mohamed M Hafez ${ }^{2 *}$
}

\begin{abstract}
Background: Diabetes mellitus (DM) and hypertension (HTN) are accused of being responsible for the development of the cardiac fibrosis due to severe cardiomyopathy.

Methods: Blood glucose (BG) test was carried out, lipid concentrations, tumor necrosis factor alpha (TNF- $\alpha$ ), transforming growth factor beta (TGF- $\beta$ ), matrix metalloproteinase (MMP-2), collagen-I and collagen-III were measured in male Albino rats weighing 179-219 g. The rats were divided into five groups, kept on either control diet or high fat diet (HFD), and simultaneously treated with rosiglitazone (PPAR-gamma) only for one group with $3 \mathrm{mg} / \mathrm{kg} /$ day via oral route for 30 days, and with rosiglitazone and felodipine combination for another group with $3 \mathrm{mg} / \mathrm{kg} /$ day and $5 \mathrm{mg} / \mathrm{kg} /$ day, respectively via oral route for 30 days.

Results: Diabetic hypertensive (DH) rats which fed on a HFD, injected with streptozotocin (STZ) (i.p.) and obstruction for its right kidney was occurred develop hyperglycemia, hypertension, cardiac fibrosis, hypertriglyceridemia, hypercholesterolemia, increased TNF- $\alpha$, increased TGF- $\beta$, decreased MMP-2, increased collagen-I and increased collagen-III, when compared to rats fed on control diet. Treating the DH rats with rosiglitazone only causes a significant decrease for BG levels by $52.79 \%$, triglycerides (TGs) by $24.05 \%$, total cholesterol (T-Chol) by 30.23\%, low density lipoprotein cholesterol (LDL-C) by $40.53 \%$, TNF- $\alpha$ by $20.81 \%$, TGF- $\beta$ by 46.54\%, collagen-I by $48.11 \%$ and collagen-III by $53.85 \%$ but causes a significant increase for MMP-2 by $272.73 \%$. Moreover, Treating the $\mathrm{DH}$ rats with rosiglitazone and felodipine combination causes a significant decrease for BG levels by $61.08 \%$, blood pressure (BP) by $16.78 \%$, TGs by $23.80 \%$, T-Chol by $33.27 \%$, LDL-C by $45.18 \%$, TNF- $\alpha$ by $22.82 \%$, TGF- $\beta$ by $49.31 \%$, collagen-I by $64.15 \%$ and collagen-III by $53.85 \%$ but causes a significant increase for MMP-2 by $290.91 \%$. Rosiglitazone alone failed to decrease the BP in DH rats in the current dosage and duration.

Conclusion: Our results indicate that the co-existence of diabetes and hypertension could induce cardiomyopathy which could further result in cardiac fibrosis, and that combination treatment with rosiglitazone and felodipine has a great protective role against the metabolic abnormalities, meanwhile, the treatment with rosiglitazone alone has a protective role with a minimal effect against these abnormalities and has no effect on decreasing BP in these cases which may lead to coronary artery diseases (CADs) in future.
\end{abstract}

\footnotetext{
* Correspondence: mohkhalifa2000@yahoo.com

${ }^{2}$ Department of Biochemistry, Faculty of Pharmacy, October for Modern

Science and Arts University (MSA), Egypt

Full list of author information is available at the end of the article
} 


\section{Introduction}

Diabetic cardiomyopathy, the leading cause of death in diabetic patients, is characterized by both systolic and diastolic dysfunction, due to reduced contractility, prolonged relaxation, and decreased compliance $[1,2]$. The development of diabetic cardiomyopathy is multifactorial. Putative mechanisms include metabolic disturbances, small vessel disease, autonomic dysfunction, insulin resistance, and myocardial fibrosis $[3,4]$. Recently interstitial fibrosis has been regarded as an important pathogenic factor of the heart's impaired functional integrity [5]; however, altered substrate supply and use by cardiac myocytes could be the primary injury in the pathogenesis of this specific heart muscle disease. Structural and functional impairment of myocytes, which occurs already in the first week of diabetes, precedes cardiac fibrosis and thus remains the key step in impairing contractile performance, finally inducing heart failure [6]. The diagnosis of a diabetic cardiomyopathy is made in patients in whom no other known etiological factors, such as coronary artery disease, or hypertension, are present [7].

Diabetes and high blood pressure are closely related diseases. They occur together so frequently that they are officially considered to be "comorbidities" (diseases likely to be present in the same patient). Unfortunately, diabetes makes high blood pressure more difficult to treat, and high blood pressure makes diabetes even more dangerous [8].

Streptozotocin (STZ) is a naturally occurring, broadspectrum antibiotic [9]. Induction of experimental diabetes in the rat using STZ is very convenient and simple to use but it is cyto-toxic chemical that is particularly toxic to the pancreatic, insulin-producing beta cells in mammals. STZ injection leads to the degeneration of the Langerhans islets beta cells [10].

One class of insulin sensitizers of the invention is Peroxisome Proliferator-Activated Receptors (PPAR) modulators, and in particular PPAR-gamma modulators, e.g., PPAR-gamma agonists. PPARs are members of the nuclear hormone receptor superfamily of ligandactivated transcription factors that are related to retinoid, steroid and thyroid hormone receptors. PPAR modulators include the PPAR-alpha, PPAR-delta (also called PPAR-beta), and PPAR-gamma agonists. Especially useful are the thiazolidinediones (TZDs), which are exogenous substances, used for clinicians in diabetic patients and not expressed in any tissue. TZDs act upon PPAR-gamma. PPAR-gamma are expressed in many tissues especially the heart [11]. They were developed in the 70's and 80's by screening newly synthesized compounds for their ability to lower blood glucose in diabetic rodents. Three molecules from this class, troglitazone, rosiglitazone, and pioglitazone, were ultimately approved for the treatment of patients with type II diabetes [12].

Although these compounds were developed without an understanding of their molecular mechanism of action, by the early 90's evidence began to accumulate linking the thiazolidinediones to the nuclear receptor PPAR-gamma. It was ultimately demonstrated that these molecules were high affinity ligands of PPAR-gamma and that they increased transcriptional activity of the receptor. Ligands of PPAR-gamma including certain thiazolidinediones, reduce myocardial tissue injury and infarct size [13-15]. TZDs PPAR-gamma activators are used clinically to improve insulin sensitivity and glycemic control in patients with Type II diabetes. PPARgamma is predominantly expressed in adipose tissue, but is also expressed in myocardium [16]. The function of PPAR-gamma in the heart suggests that activation of myocardial PPAR-gamma may have metabolic and antiinflammatory effects. PPAR-gamma activation has been shown to increase myocardial expression of glucose transporters, promote carbohydrate substrate utilization in cardiac myocytes and intact hearts $[17,18]$, and attenuate pro-inflammatory cytokine expression in activated cardiomyocytes [19], experimental myocarditis [20] or chronic LV failure due to myocardial infarction [21]. Moreover, most studies have shown that TZDs PPAR-gamma activators reduce myocardial infarct size and enhance recovery of contractile function in intact rat hearts after ischemia and reperfusion. These findings are derived from studies in both normal and insulin resistant models $[17,18,22,23]$.

Metabolic syndrome is associated with accelerated macrovascular and microvascular coronary disease, cardiomyopathy, and elevated inflammatory status [24-27]. Felodipine (which used as calcium channel blocker) administration can attenuate the inflammatory and fibrosis process. As felodipine is used for treating high blood pressure. This medication helps to relax the blood vessels, which improves blood flow and makes it easier for the heart to pump blood. It has a direct beneficial effect by inhibiting the nuclear translocation and DNAbinding activity of nuclear factor $-\kappa \mathrm{B}$, which plays a central role in this process by regulating the expression of several proinflammatory genes [28].

TNF- $\alpha$ is an acute phase reactive protein and a basic medium of immunological regulation, and it is also an inflammatory cytokine with pleiotropic biological effects. In the circulatory system, TNF- $\alpha$ is responsible for many myocardial diseases such as acute coronary syndrome [29], Acute myocardial infarction (AMI) [30,31], myocarditis [32], dilated cardiomyopathy and congestive heart failure (CHF) [33,34]. 
TGF- $\beta 1$ facilitates fibrous tissue formation, upregulates collagen expression by stimulating extracellular matrix synthesis, and mediates perivascular and myocardial fibrosis. The increased gene expression of extracellular matrix (ECM) components, such as collagen, and of TGF- $B 1$ causes cardiac fibrosis and promotes cardiac stiffness, leading to diastolic dysfunction [35].

Myocardial stunning was attenuated by inhibition of MMP-2 activity [36,37]. In the setting of heart failure, MMP-2 has been implicated in myocardial fibrosis, increased myocardial stiffness and impaired contractility of hearts from spontaneously hypertensive rats [38].

Cardiac fibroblasts are the most abundant cell type of the myocardium and produce various proteins found in ECM, including the major fibrillar collagens type I and III, which comprise the bulk of the ECM, as well as collagenases, fibronectin, and vitronectin [39].

Calcium channel blockers (CCBs) are widely used to treat cardiovascular diseases [40].

In this study, we investigate the role of CCBs (felodipine) and PPAR-gamma modulators on blood glucose level, blood pressure, lipid profile, TNF- $\alpha$, TGF- $\beta 1$, MMP-2, collagen-I and collagen-III in DH rats.

\section{Materials and methods Chemicals}

Glucose (Spectrum Diagnostics, Cairo, Egypt). STZ (Sigma chemical Company, Saint Louis, MO, USA).

\section{Diet}

The diet for forty rats were fed a high-fat diet consists of $22.5 \%$ hydrogenated vegetable oil, $22.5 \%$ milk powder, $51.5 \%$ soybean ground, $2 \%$ corn starch, $1 \%$ sucrose and $0.5 \%$ vitamins and minerals.

\section{Animals}

Fifty male Albino rats were used for the present study after being procured from the animal house of El-Nile Company for Pharmaceutical Products (Cairo, Egypt). The animals were acclimatized for two weeks in the animal house of Zagazig University before dietary manipulation. After two weeks of high-fat diet, induction of diabetes was occurred, as rats were overnight fasted and injected intra-peritoneal (i.p.) with $35 \mathrm{mg} / \mathrm{kg}$ STZ (Sigma chemical Company, Saint Louis, MO, USA) freshly prepared in cold $0.1 \mathrm{~mol}$ citrate buffer $(\mathrm{pH} 4.5)$ [41]. One week after the injection of STZ hyperglycemic state was first tested by detection of glucosuria using urine glucose strips. Rats with two successive blood glucose levels more than $300 \mathrm{mg} / \mathrm{dl}$ were used in this study. Thus streptozotocin injury was occurred.

Then, induction of hypertension was occurred, as thirty diabetic rats were anesthetized injection of sodium thiopental (12 mg/100 gm) [42]. After anesthesia, the animal was fixed in supine position on the operating table and the abdominal skin was shaved and sterilized with $70 \%$ ethyl alcohol. Then, a midline incision was made, and the right renal artery was clamped for $45 \mathrm{~min}$ utes using a non-traumatic vascular clamp (Bulldog clamp). Then, the edges of the abdominal incision were approximated to each other and covered by a piece of gauze soaked with warm isotonic saline $\left(37^{\circ} \mathrm{C}\right)$ to prevent undue loss of body fluids. Reperfusion achieved after 15 minutes from removal of the vascular clamp on the right renal artery [43].

Two rats were housed per wire floored cage in an airconditioned room $\left(22 \pm 2^{\circ} \mathrm{C}\right)$ with $12 \mathrm{~h}$ light/dark cycle and had free access to standard laboratory chow diet (El Nasr Co, Cairo, Egypt), and water ad libitum. The protocol of the current study was approved by the department of Biochemistry Council, Faculty of Pharmacy, Zagazig University, which has an ethical authority.

\section{Experimental design}

Animals weighed 179-219 $\mathrm{g}$ at the time of dietary manipulation. They were randomly assigned into five groups of ten each, as given below:

i. Control group (C): Normal control healthy rats.

ii. Diabetic Control group (DC): Diabetic control rats, that took fat diet for two weeks then injected with STZ intraperitoneal (i.p.).

iii. Diabetic Hypertensive Control group (DHC): Type 2 DM hypertensive rats, that took fat diet for two weeks then injected with STZ i.p. Finally, obstruction for right kidney was done for all of them for induction of hypertension.

iv. DH rats + Rosiglitazone (R): Treated DH rats with PPAR-gamma (Rosiglitazone) with a dose of $3 \mathrm{mg} / \mathrm{kg} /$ day [44] orally only for one month.

v. DH rats + combination of Rosiglitazone and Felodipine $(\mathrm{R}+\mathrm{F})$ : Treated $\mathrm{DH}$ rats with a combination of PPAR-gamma (Rosiglitazone) with a dose of $3 \mathrm{mg} / \mathrm{kg} /$ day orally and CCB (Felodipine) with a dose of $5 \mathrm{mg} / \mathrm{kg} /$ day [45] orally for one month.

The animals were maintained in their respective groups for 30 days. Fasting serum glucose level, blood pressure, lipid profile, TNF- $\alpha$, TGF- $\beta 1$, MMP-2, collagen-I and collagen-III of all animals were measured at the last day (day 30) of the experiment.

\section{Blood Sample collection}

Blood samples were collected from retro-orbital plexus of the eye after 30 days from 12-h fasted rats into vacutainer clotted tubes, where sera were obtained by centrifugation within $30 \mathrm{~min}$ at $4000 \mathrm{rpm}$ at $4^{\circ} \mathrm{C}$ for $10 \mathrm{~min}$ using Centurion centrifuge (K280R, UK), then divided 
into aliquots and kept at $-80^{\circ} \mathrm{C}$ for further assay of lipid profile and TNF- $\alpha$ while serum glucose was determined immediately.

\section{Harvesting of left ventricle specimen}

The left ventricle of heart was removed rapidly and cut into two equal halves by a scalpel. One half of it was rapidly placed in $10 \%$ neutral buffered formalin for immunostaining and the other half was rapidly frozen in liquid nitrogen, and stored at $-72^{\circ} \mathrm{C}$ for real time polymerase chain reactions (RT-PCR) assessments for TGF$\beta 1$, MMP-2, collagen-I and collagen-III [46].

\section{Histological examination}

1) The selected paraffin blocks for immunohistochemical staining were sectioned (4- $\mu \mathrm{m}$ thickness) and stained with hematoxylin and eosin (H\&E) stain [47].

2) Masson trichrome stain [48]: The data were obtained using Leica Qwin 500 image analyzer computer system (England). The image analyzer consisted of a coloured video camera, coloured monitor, hard disc of IBM personal computer connected to the microscope, and controlled by Leica Qwin 500 software. The image analyzer was first calibrated automatically to convert the measument units (pixels) produced by the image analyzer program into actual micrometer units.

The area \% of CT fibers was measured using an objective lens of magnification 10, i.e of a total magnification of 100. Ten fields were measured for each specimen. Using the colour detect, CT areas were masked by a blue binary colour. The area \% was calculated in relation to a standard measuring frame of area 118476.6 micrometer square.

The data obtained were subjected to statistical analysis using t-student's test and ANOVA.

\section{Biochemical measurements}

The concentration of serum glucose was measured by the enzymatic colorimetric GOD-POD procedure [49] using Diamond Diagnostic kit (Germany).

Serum TGs were estimated by GPO-POD enzymatic method [50] using a Biocon kit (India). T-Chol concentration was determined utilizing enzymatic colorimetric CHOD-PAP method [51] using Biocon kit (India). HDL$\mathrm{C}$ was determined by the same method after the precipitation of very low density lipoprotein cholesterol (VLDL-C) and LDL-C [52], and finally, LDL-C was calculated by Using Friedewald's Formula [53]:

$$
\operatorname{LDL}(\mathrm{mg} / \mathrm{dl})=\mathrm{TC}-(\mathrm{HDL}-\mathrm{C}+\mathrm{TAG} / 5) \text {. }
$$

Serum TNF- $\alpha$ was assessed by the rat TNF- alpha enzyme-linked immunosorbent assay (ELISA) kit which is an in vitro enzyme-linked immunosorbent assay for the quantitative measurement of rat TNF- alpha cell lysate and tissue lysate [54].

For the detection of collagen-I, collagen-III, TGF- $\beta$ and MMP-2 gene expression, RNA was extracted, reverse transcribed into cDNA and amplified by PCR. Total RNA was extracted from heart tissue using SV Total RNA Isolation System (Promega, Madison, WI, USA). The extracted RNA was reverse transcribed into cDNA using RT-PCR kit (Stratagene, USA). Then amplification of specific DNA sequences using two primers that hybridize to opposite strands and flank target DNA region. At the end of the amplification process, the DNA product was detected using agarose gel electrophoresis.

\section{Statistical analysis}

The results were expressed as mean \pm SD. To determine the statistical significance of laboratory findings, multiple comparisons were achieved using independent samples T- Test and ANOVA followed by Tukey test as post hoc test. The correlations between BG and TNF- $\alpha$ were tested by Pearson's coefficient (r). P-value $\leq 0.05$ was considered statistically significant.

\section{Results}

DC animals showed significant increase in their serum glucose levels by $278.88 \%$ in comparison with group C. Furthermore, DHC animals showed also significant increase in their serum glucose levels by $35.15 \%$ in comparison with DC animals group. However, group R and group $\mathrm{R}+\mathrm{F}$ induced significant decrease in their serum glucose levels by $(52.79 \%$ and $61.08 \%$ respectively) in comparison with DHC data (Table 1).

DC animals showed significant increase in their BP levels by $25.52 \%$ in comparison with group C. Furthermore, DHC animals showed also significant increase in their BP levels by $23.42 \%$ in comparison with DC animals group. But there is no significance between group $\mathrm{R}$ and DHC data in its BP levels. However, group $\mathrm{R}+\mathrm{F}$ induced significant decrease in their BP levels by $16.78 \%$ in comparison with DHC data (Table 1).

DC animals showed significant increase in their TGs levels by $20.06 \%$ in comparison with group C. But, DHC animals showed no significance in their TAG levels in comparison with DC animals group. Meanwhile, there was nearly the same significant decrease between group $\mathrm{R}$ and group $\mathrm{R}+\mathrm{F}$ in their TAG levels by $(24.05 \%$ and $23.80 \%$ respectively) in comparison with DHC data (Table 2).

DC animals showed a significant increase in their $\mathrm{T}$-Chol levels by $45.89 \%$ in comparison with group C. Furthermore, DHC animals showed also a significant increase in their T-Chol levels by $17.05 \%$ in comparison with $\mathrm{DC}$ animals group. At the other side, there was a 
Table 1 Effect of STZ and obstruction for right kidney on fasting serum glucose and blood pressure

\begin{tabular}{cccccc}
\hline & \multicolumn{5}{c}{ Groups } \\
\hline & Control & Diabetic Control & Diabetic Hypertensive Control & Rosiglitazone & Rosiglitazone+Felodipine \\
\hline Glucose $(\mathrm{mg} / \mathrm{dL})$ & $98.00 \pm 9.61$ & $371.30 \pm 39.09 \wedge$ & $501.80 \pm 54.44^{*}$ & $236.90 \pm 47.98 \#$ & $195.30 \pm 47.35 \#$ \\
\hline Blood Pressure $(\mathrm{mmHg})$ & $126.20 \pm 4.78$ & $158.40 \pm 14.09 \wedge$ & $195.50 \pm 13.26^{*}$ & $189.90 \pm 13.16$ & $162.70 \pm 16.73 \# \mathrm{a}$ \\
\hline
\end{tabular}

Values are expressed as mean \pm SD. Number of rats per group $n=10$.

STZ, streptozotocin.

$\wedge$ Significant difference from normal control at $\mathrm{P}<0.05$.

* Significant difference from diabetic control at $\mathrm{P}<0.05$

\# Significant difference from diabetic hypertensive control at $P<0.05$.

a Means of treated groups with different superscript are significantly different from each other at $P<0.05$.

significant decrease between group $\mathrm{R}$ in comparison to $\mathrm{DHC}$ group in their T-Chol levels by $30.23 \%$. Also there was a significant decrease between the group $\mathrm{R}+\mathrm{F}$ in their T-Chol levels by $33.27 \%$ in comparison with DHC data (Table 2).

HDL-C levels decreased significantly in DC animals in comparison with group $C$ by a level of $20.93 \%$. Also, there was a significant decrease between DHC data in their HDL-C levels by $6.92 \%$ in comparison with DC data. Meanwhile, there was nearly the same significant increase in group $R$ and the group $R+F$ levels by (20.95\% and $24.51 \%$ respectively) in comparison with DHC data (Table 2).

LDL-C levels showed a significant increase in DC animals by $92.45 \%$ in comparison with group C. Also, there was a significant increase in DHC animals in their LDLC levels by $24.9 \%$ in comparison with DC data. On the other hand, LDL-C levels decreased significantly in group $\mathrm{R}$ in comparison with $\mathrm{DHC}$ group by a level of 40.53\%. Moreover, LDL-C levels decreased significantly in the group $\mathrm{R}+\mathrm{F}$ in comparison with $\mathrm{DHC}$ group by a level of $45.18 \%$ (Table 2).

There is a significant increase in TNF- $\alpha$ level in DC group by $22.59 \%$ in comparison with group C. Furthermore, DHC animals showed also significant rise in their TNF- $\alpha$ levels by $10.23 \%$ in comparison with DC animals group. However, group $\mathrm{R}$ and group $\mathrm{R}+\mathrm{F}$ induced nearly the same significant decrease in their TNF- $\alpha$ level by (20.81\% and $22.82 \%$ respectively) in comparison with DHC data (Table 2, Figure 1).

TGF- $\beta$ levels showed a significant rise in DC group by $89.62 \%$ in comparison with group C. But, DHC group showed no significance in their TGF- $\beta$ levels in comparison with $\mathrm{DC}$ group. However, group $\mathrm{R}$ and group $\mathrm{R}+\mathrm{F}$ induced nearly the same significant decrease in their TGF- $\beta$ levels by ( $46.54 \%$ and $49.31 \%$ respectively) in comparison with DHC group data (Table 2, Figure 2).

MMP-2 levels DC showed a significant decrease in DC group by $92.68 \%$ in comparison with group C. But, DHC group showed a significant rise in their MMP-2 levels by

Table 2 Measurements of fasting serum lipids, TNF- $\alpha$, TGF- $\beta$, MMP-2, collagen-I, collagen-III and masson trichrome

\begin{tabular}{lccccc}
\hline & \multicolumn{5}{c}{ Groups } \\
\hline & Control & Diabetic Control & Diabetic Hypertensive Control & Rosiglitazone & Rosiglitazone + Felodipine \\
\hline TGs $(\mathrm{mg} / \mathrm{dL})$ & $79.50 \pm 2.65$ & $95.45 \pm 6.38 \wedge$ & $98.95 \pm 7.29$ & $75.15 \pm 4.94 \#$ & $75.40 \pm 7.31 \#$ \\
\hline T-Chol $(\mathrm{mg} / \mathrm{dL})$ & $133.38 \pm 7.17$ & $194.59 \pm 14.36 \wedge$ & $227.76 \pm 19.94^{*}$ & $158.90 \pm 6.82 \#$ & $151.98 \pm 6.83 \# a$ \\
\hline $\mathrm{LDL}-\mathrm{C}(\mathrm{mg} / \mathrm{dL})$ & $72.86 \pm 9.39$ & $140.22 \pm 14.91 \wedge$ & $175.13 \pm 19.69^{*}$ & $104.15 \pm 7.64 \#$ & $96.01 \pm 8.08 \# \mathrm{a}$ \\
\hline $\mathrm{HDL}-\mathrm{C}(\mathrm{mg} / \mathrm{dL})$ & $44.62 \pm 3.62$ & $35.28 \pm 2.22 \wedge$ & $32.84 \pm 1.62^{*}$ & $39.72 \pm 2.47 \#$ & $40.89 \pm 2.77 \#$ \\
\hline TNF- $\alpha(\mathrm{ng} / \mathrm{mL})$ & $203.19 \pm 10.88$ & $249.10 \pm 13.73 \wedge$ & $274.58 \pm 17.38^{*}$ & $217.45 \pm 18.23 \#$ & $211.93 \pm 17.91 \#$ \\
\hline TGF- $\beta$ & $1.06 \pm 0.09$ & $2.01 \pm 0.23 \wedge$ & $2.17 \pm 0.29$ & $1.16 \pm 0.10 \#$ & $1.10 \pm 0.07 \#$ \\
\hline MMP-2 & $0.82 \pm 0.09$ & $0.06 \pm 0.04 \wedge$ & $0.11 \pm 0.05^{*}$ & $0.41 \pm 0.12 \#$ & $0.43 \pm 0.22 \#$ \\
\hline Collagen-I & $0.11 \pm 0.04$ & $0.80 \pm 0.21 \wedge$ & $1.06 \pm 0.27^{*}$ & $0.55 \pm 0.09 \#$ & $0.38 \pm 0.11 \# a$ \\
\hline Collagen-III & $0.06 \pm 0.02$ & $0.11 \pm 0.03 \wedge$ & $0.13 \pm 0.06$ & $0.06 \pm 0.02 \#$ & $0.06 \pm 0.02 \#$ \\
\hline Masson trichrome & $13.54 \pm 1.31$ & $10.79 \pm 1.86 \wedge$ & $22.34 \pm 6.29^{*}$ & $8.79 \pm 1.44 \#$ & $10.45 \pm 2.96 \#$ \\
\hline Val & & &
\end{tabular}

Values are expressed as mean \pm SD. Number of rats per group $n=10$.

STZ, streptozotocin; TGs, triglycerides; T-Chol, total cholesterol; LDL-C, low density lipoprotein cholesterol; HDL-C, high density lipoprotein cholesterol; TNF- $\alpha$, tumor necrosis factor alpha; TGF- $\beta$, transforming growth factor beta; MMP-2, matrix metalloproteinase-2.

$\wedge$ Significant difference from normal control at $\mathrm{P} \leq 0.05$.

* Significant difference from diabetic control at $P \leq 0.05$.

\# Significant difference from diabetic hypertensive control at $\mathrm{P} \leq 0.05$.

a Means of treated groups with different superscript are significantly different from each other at $P \leq 0.05$. 


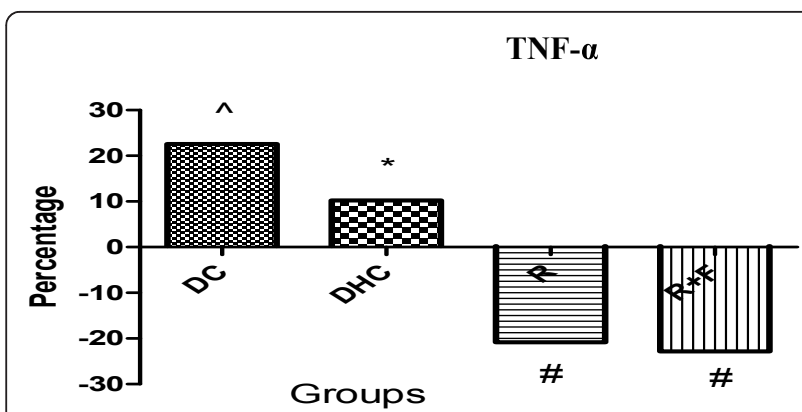

Figure 1 Percentage change of TNF- $\alpha$ in group DC; group DHC; group $\mathrm{R}$ and group $\mathrm{R}+\mathrm{F}$ for one month. Each value is expressed in $\mathrm{ng} / \mathrm{mL}$. ( $\wedge$ ) Significant difference from normal control at $P<0.05$. (*) Significant difference from diabetic control at $P<$ 0.05. (\#) Significant difference from diabetic hypertensive control at $P<0.05$. Using one way ANOVA followed by Tukey test as post hoc test.

83.33\% in comparison with DC group. However, group $\mathrm{R}$ and group $\mathrm{R}+\mathrm{F}$ data induced nearly the same significant rise in their MMP-2 levels by $(272.73 \%$ and $290.91 \%$ respectively) in comparison with DHC group data (Table 2, Figure 3).

Our results revealed that, there is no significant difference between TGF- $\beta$ and MMP-2

There was a significant rise in their collagen I levels in DC group by $627.27 \%$ in comparison with group C. Furthermore, DHC animals showed also significant rise in their collagen I levels by $32.50 \%$ in comparison with DC animals group. However, group R induced a significant decrease in their collagen I levels by $48.11 \%$ in comparison with $\mathrm{DHC}$ data group. Also, group $\mathrm{R}+\mathrm{F}$ induced a significant decrease in their collagen I levels by $64.15 \%$ in comparison with DHC data group (Table 2, Figure 4).

There was a significant rise in their collagen III levels in DC group by $83.33 \%$ in comparison with group C. But, DHC group showed no significance in their

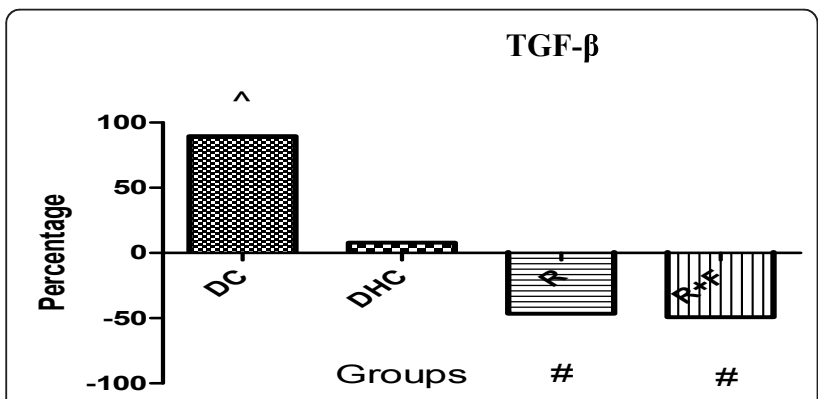

Figure 2 Percentage change of TGF- $\beta$ in group DC; group DHC; group $\mathbf{R}$ and group $\mathbf{R}+\mathbf{F}$ for one month. $(\wedge)$ Significant difference from normal control at $P<0.05$. (\#) Significant difference from diabetic hypertensive control at $P<0.05$. Using one way ANOVA followed by Tukey test as post hoc test.

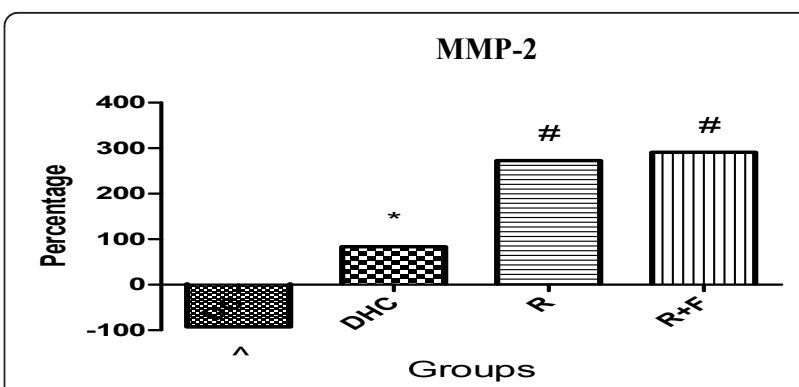

Figure 3 Percentage change of MMP-2 in group DC; group DHC; group $\mathbf{R}$ and group $\mathbf{R}+\mathbf{F}$ for one month. $(\wedge)$ Significant difference from normal control at $P<0.05$. $\left.{ }^{*}\right)$ Significant difference from diabetic control at $P<0.05$. (\#) Significant difference from diabetic hypertensive control at $P<0.05$. Using one way ANOVA followed by Tukey test as post hoc test.

collagen III levels in comparison with DC animals group. However, group $\mathrm{R}$ and group $\mathrm{R}+\mathrm{F}$ induced the same significant decrease in their collagen III levels by nearly $53.85 \%$ in comparison with DHC data group (Table 2, Figure 5).

Light microscope examination of H\&E stained sections of the cardiac muscle of the group $C$ rats revealed that the cardiac muscle fibers are connected end to end by intercalated discs appeared with central and oval vascular nuclei.

$\mathrm{H} \& \mathrm{E}$ stained sections of the cardiac muscle of the DC group rats showed degeneration in some of the cardiac muscle fibers in the form of separation and fragmentation of the cardiac muscle fibers.

Examination of $H \& E$ stained sections of the cardiac muscle of the DHC group rats showed longitudinal section in the cardiac muscle fibers showing hypertrophy of the cardiomyocytes.

The cardiac muscle fibers of rats receiving rosiglitazone treatment alone showed mild fragmentation and

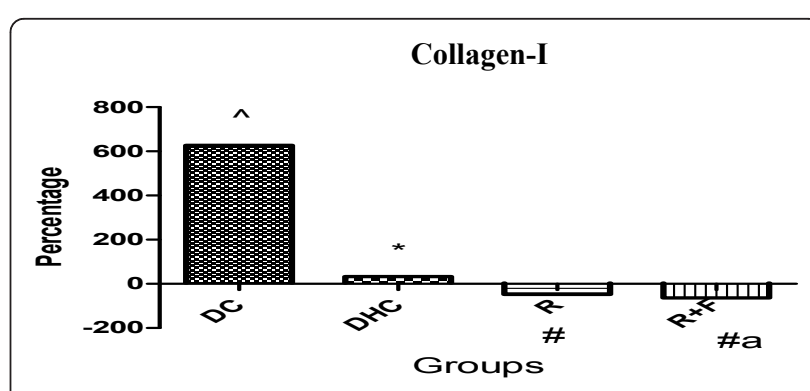

Figure 4 Percentage change of collagen-I in group DC; group DHC; group $\mathbf{R}$ and group $\mathbf{R}+\mathbf{F}$ for one month. $(\wedge)$ Significant difference from normal control at $P<0.05$. $\left(^{*}\right)$ Significant difference from diabetic control at $P<0.05$. (\#) Significant difference from diabetic hypertensive control at $P<0.05$. a....., Means of treated groups with different superscript are significantly different from each other at $P<0.05$. Using one way ANOVA followed by Tukey test as post hoc test. 


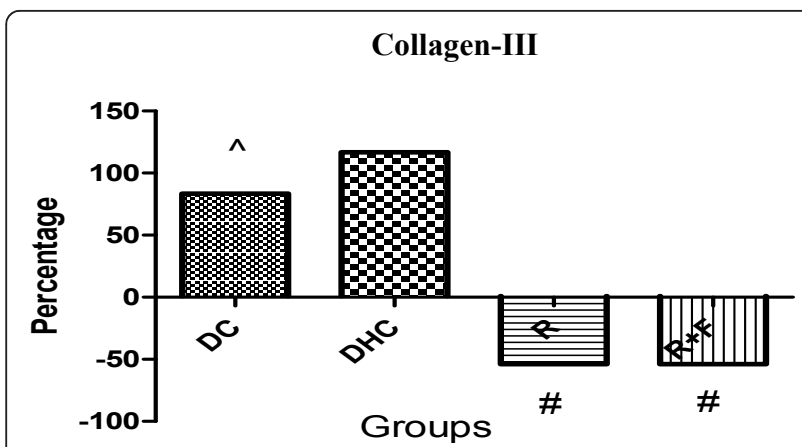

Figure 5 Percentage change of collagen-III in group DC; group DHC; group $\mathrm{R}$ and group $\mathrm{R}+\mathrm{F}$ for one month. $(\wedge)$ Significant difference from normal control at $P<0.05$. $\left(^{*}\right)$ Significant difference from diabetic control at $P<0.05$. (\#) Significant difference from diabetic hypertensive control at $P<0.05$. Using one way ANOVA followed by Tukey test as post hoc test.

degeneration of the cardiomyocytes in H\&E stained sections.

Histological examination of H\&E stained sections of the cardiac muscle fibers of rats receiving combined treatment of rosiglitazone and felodipine revealed a nearly normal appearance of the cardiac muscle fibers with no fosi of degeneration.

Our results illustrated that, there was a significant decrease in their area percentage of masson trichrome stained connective tissue (CT) fibers of cardiac muscle levels in DC group by $20.285 \%$ in comparison with group C. Meanwhile, DHC rats showed a significant increase in their area percentage of masson trichrome stained CT fibers levels by $106.975 \%$ in comparison with $\mathrm{DC}$ rats group. However, group $\mathrm{R}$ induced a significant decrease in their area percentage of masson trichrome stained CT fibers levels by $60.67 \%$ in comparison with $\mathrm{DHC}$ data group. Also, group $\mathrm{R}+\mathrm{F}$ induced a significant decrease in their area percentage of masson trichrome stained CT fibers levels by $53.24 \%$ in comparison with DHC data group. Moreover, there is no significant difference between $\mathrm{R}$ group and $\mathrm{R}+\mathrm{F}$ group rats (Table 2, Figure 6).

\section{Discussion}

Diabetes is a growing global health problem with type 2 DM being now an epidemic [55]. The major clinical consequences of type $2 \mathrm{DM}$ are mortality and morbidity from vascular complications [56]. Moreover patients with type $2 \mathrm{DM}$ have an increased risk of premature development and accelerated progression of atherosclerosis [57].

The pathogenesis of CVD in DM is multi-factorial and can be affected by many factors such as hyperglycemia, increased production of fatty acids, and altered

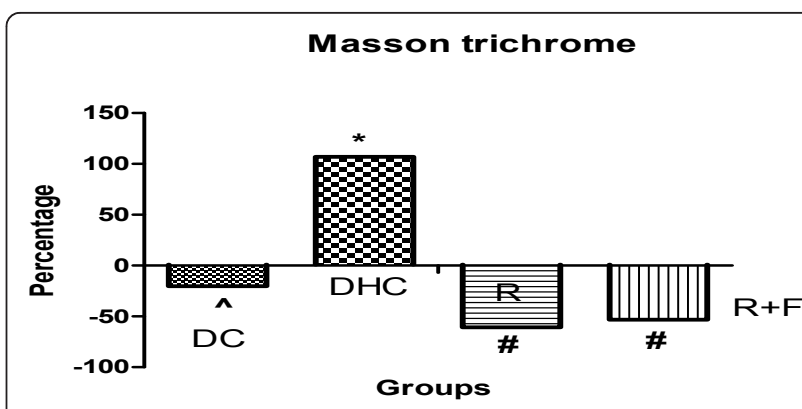

Figure 6 Percentage change of masson trichrome in group DC; group DHC; group $\mathrm{R}$ and group $\mathrm{R}+\mathrm{F}$ for one month. $(\wedge)$ Significant difference from normal control at $P<0.05$. $\left(^{*}\right)$ Significant difference from diabetic control at $P<0.05$. (\#) Significant difference from diabetic hypertensive control at $P<0.05$. Using one way ANOVA followed by Tukey test as post hoc test.

lipoproteins [58]. Recently, important factors were proposed to initiate $\mathrm{CV}$ complications in type $2 \mathrm{DM}$, including cardiac fibrosis and inflammation [59]. Consequently, there have been considerable recent efforts to focus on non-traditional risk factors for CV events in type $2 \mathrm{DM}$ patients' population.

Streptozotocin (STZ) is a synthetic antineoplastic agent that is classifically an anti-tumor antibiotic and chemically is related to other nitrosureas used in cancer chemotherapy. STZ injury, induced diabetes can begin an autoimmune process that results in destruction of the Langerhans islets beta cells and toxicity of beta cells of pancreas with emergence of clinical diabetes within 2-4 days [60].

The result of our study explained that, in STZinduced diabetic and DH groups when compared to the normal control healthy group, there was a significant increase in BG. This result was consistent with many studies [60-63].

Our study explained that, there was a significant increase in BG levels between DC and DHC rats (group II and III, respectively) compared with group C. Also this is supported by a significant positive correlation between BG and BP. This study is confirmed with the study of [64].

In the contrary, rosiglitazone showed a significant decrease in BG levels in treated groups (groups $\mathrm{R}$ and $\mathrm{R}$ $+F$, respectively). But there is no significantly decrease in group $\mathrm{R}+\mathrm{F}$ which is treated with rosiglitazone and felodipine combination in comparison to group $\mathrm{R}$ which is treated with rosiglitazone only. This study is consistent with [62].

From these data, it is clear that rosiglitazone which acts as peroxisome proliferator activated receptor gamma had the greatest role in treatment of DM. But at the other hand, there was no role for felodipine in 
treatment of DM, so there is no significant decrease in BG when felodipine was added to treatment.

Hypertension is a major risk factor for CHD and can induce several other risk factors [65]. Hence, regarding the blood pressure; BP was elevated in the DC and DHC rats (groups II and III, respectively) compared with group $C$. This was also the case in the studies conducted on hypertensive type 2 DM patients [66]. Furthermore, this is supported by a positive correlation between BG and BP.

In the contrary, there is a significant decrease in group $\mathrm{V}$ which is treated with rosiglitazone and felodipine combination due to felodipine effect in comparison to DHC rats (group III). But on the other hand, there is no significant decrease in group $\mathrm{R}$ which is treated with rosiglitazone only in comparison to DHC rats (group III).

From these data, it is obvious that treatment combination of rosiglitazone and felodipine had the upper hand in decreasing BP over rosiglitazone treatment only because of the role of felodipine which acts as calcium channel blocker [67].

It is reported that prolonged exposure to hyperglycemia is recognized as the primary casual factor in the pathogenesis of diabetic cardiac complications. Even in the upper limits of normal range and independent of other known risk factors, hypertension could be predictor of coronary events $[68,69]$. These findings confirm that hyperglycemia induces a large number of alterations in the cardiac tissue that potentially promote increasing of interstitial fibrosis and myocyte apoptosis [70,71]. Several studies have attempted to find the link between hyperglycemia and development of coronary atherosclerosis [72,73]. Therefore, the highest BG and BP values were observed in DHC group.

We should be aware of the important relationship between type $2 \mathrm{DM}$ and cardiac fibrosis.

Hence, the present study was conducted aiming to evaluate the role of lipid profile, TNF- $\alpha$, TGF- $\beta$, Collagen I, Collagen III and MMP-2 in type 2 DM hypertensive patients who developed cardiac fibrosis. Correlating these parameters in the DHC groups, as well as their relation with glycemic status was also a target in this study. In order to achieve our aim, we assessed the levels of these biochemical markers in DHC rats with and without cardiac fibrosis and compared them with group C. This was done in an attempt to explore the possible relationships between hyperglycemia, hypertension, dyslipidemia and inflammation as well as cardiac fibrosis.

It was stated that dyslipidemia is a recognized risk factor for CVD in DM. In our study, all diabetic rats showed significant dyslipidemia compared with the healthy control subjects. It was found that the levels of
TAG, T-Chol, and LDL-C were significantly increased in DC and DHC groups (II and III, respectively) as compared to the group $\mathrm{C}$. On the other hand, the level of HDL-C was significantly reduced in both groups, as compared to the group C. Furthermore, this fact is supported with a significant positive correlation between BG and T- Chol [74].

In the contrary, there was a significant increase for HDL-C in group $\mathrm{R}$ which was treated with rosiglitazone only and group $\mathrm{R}+\mathrm{F}$ which was treated with combination of rosiglitazone and felodipine in comparison to $\mathrm{DHC}$ rats. But there was no significant difference between group $\mathrm{R}+\mathrm{F}$ and group $\mathrm{R}$. It is obvious that there is no great role for felodipine in increasing HDL-C for DH rats.

Furthermore, there was a significant increase for T-Chol in DC and DHC groups (II and III, respectively).

But, there was a significant decrease for T-Chol in group $\mathrm{R}$ which was treated with rosiglitazone only and group $\mathrm{R}+\mathrm{F}$ which was treated with combination of rosiglitazone and felodipine in comparison to $\mathrm{DH}$ rats. And also, there is a significant decrease for $\mathrm{T}$-Chol in group $\mathrm{R}$ and $\mathrm{R}+\mathrm{F}$.

The work was reported that; when raised TAG coexists with an atherogenic $\mathrm{T}$-Chol profile, the overall risk of atherosclerosis is enhanced. The more features of metabolic syndrome; a rat has the greater the risk which is made much worse by concomitant LDL-C elevation $[75,76]$.

Hyperglycemia may be associated with proatherogenic modifications to plasma lipoproteins [77]. TNF- $\alpha$ is one of the key inflammatory mediators expressed during a variety of inflammatory conditions, and takes part in a variety of physiological and pathological phenomena as increasing of its expression in coronary arteries [78].

In our study, there was a significant increase in DC and DHC rats groups (II and III, respectively) as compared with group C. Also there was a significant decrease for TNF- $\alpha$ in group $\mathrm{R}$ which was treated with rosiglitazone only and in group $\mathrm{R}+\mathrm{F}$ which was treated with combination of rosiglitazone and felodipine in comparison to DHC rats. Furthermore there was no significant difference between group $\mathrm{R}$ and $\mathrm{R}+\mathrm{F}$.

These findings confirm that felodipine has no any role in improvement of TNF- $\alpha$ expression in cardiac fibrosis cases. So it is obvious that there is a potent relation between increasing of TNF- $\alpha$ expression and (CADs) [79]. Also, this is supported with a significant positive correlation between BG and TNF-alpha.

The myocardium is composed of cardiac myocytes enveloped in a dense extracellular network of collagen, the main structural protein. Cardiac myocytes account for $70 \%$ to $75 \%$ of the myocardium by cell volume but only $25 \%$ to $30 \%$ by cell number [80]. 
Cardiac fibroblasts are the most abundant cell type of the myocardium and produce various proteins found in the extracellular matrix (ECM), including the major fibrillar collagens type I and III, which comprise the bulk of the ECM, as well as collagenases, fibronectin, and vitronectin [81].

Our study explained that, there was a significant increase for collagen I in DC and DHC rats groups (II and III, respectively) in comparison to group $C$ (group I).

On the other hand, there was a significant decrease in group $\mathrm{R}$ which was treated with rosiglitazone only and group $\mathrm{R}+\mathrm{F}$ which was treated with rosiglitazone and felodipine combination in comparison to DHC rats (group III).

Furthermore, there was a significant decrease within groups ( $\mathrm{R}$ and $\mathrm{R}+\mathrm{F}$ ), this elucidates that group $\mathrm{R}+\mathrm{F}$ which was treated with rosiglitazone and felodipine combination is more potent action on collagen I than group $\mathrm{R}$ which was treated with rosiglitazone only.

These findings confirm that the treatment with combination of rosiglitazone and felodipine has the upper hand on treatment with rosiglitazone alone which clarify that, this combination has a great role on attenuating cardiac perivascular fibrosis due to the presence of felodipine which acts as calcium channel blocker due to the blood pressure regulation. And also, there was a significant increase for collagen III in DC and DHC rats in groups (II and III, respectively) in comparison to group $\mathrm{C}$ (group I). But there was no significant difference within groups (DC and DHC). But, there was a significant decrease in group $\mathrm{R}$ which was treated with rosiglitazone only and in group $\mathrm{R}+\mathrm{F}$ which was treated with rosiglitazone and felodipine combination when compared with DHC rats (group III). It is obvious that, there was no significantly difference between group $\mathrm{R}$ and group $\mathrm{R}+\mathrm{F}$. It is confirmed that there was no correlation between blood glucose and collagen III, but there was a positive correlation between BP and collagen III. So it is cleared that the addition of felodipine to treatment has no effect on improvement of collagen III. This result is opposed with the study of [40].

TGF- $\beta$ is a multifunctional cytokine that acts on a wide assortment of cell types regulating both cell growth and differentiation. TGF- $\beta$ can have potent inhibitory effects on $\mathrm{T}$-cell proliferation, cytokine production, and cytolytic functions [82].

Our study showed a significant increase of TGF- $\beta$ in DC and DHC rats in groups (II and III, respectively) in comparison to group C (group I). But, there was no significantly difference between groups (DC and DHC).

On the other hand, there was a significant decrease in group $\mathrm{R}$ which was treated with rosiglitazone only and group $\mathrm{R}+\mathrm{F}$ which was treated with rosiglitazone and felodipine combination in comparison to DHC rats (group III). But, at the same time, there was no significantly difference between groups ( $R$ and $R+F)$.

It is clear that, the results of TGF- $\beta$ clarified that treated groups even with rosiglitazone only (group R) or with rosiglitazone and felodipine combination (group $\mathrm{R}$ $+\mathrm{F}$ ) are nearly near to group $\mathrm{C}$ (group I). The conclusion for TGF- $\beta$ shows that it is a very good indicator for determination of cardiac fibrosis as TGF- $\beta_{1}$ is produced normally at low levels in cardiac tissue. However, when myocardial injury occurs, TGF- $\beta_{1}$ is released in large quantities by injured myocytes, fibroblasts, infiltrating macrophages and lymphocytes. [83] is consistent with our study.

MMPs are an endogenous family of proteolytic enzymes that play an important role in extracellular matrix (ECM) turnover and cardiac remodeling. The MMP family consists to date of more than 20 species including collagenases (such as MMP-1 and MMP-13), gelatinases (such as MMP-2 and MMP-9), stromelysin (MMP-3) and membranous type MMP (such as MT1MMP). MMP-2 is produced by cardiomyocytes, cardiac fibroblasts and endocardial cells. Alterations in the expression and activity of MMP-2 have been demonstrated in a number of pathophysiological conditions. As increased MMP-2 expression should result in a decreased level of cardiac interstitial collagen, in which large increases in gelatinase activity were associated with increased total collagen content. In the setting of myocardial ischemia/reperfusion, acutely elevated MMP-2 activity contributes to myocardial stunning in human and rat hearts, independent of an effect on the ECM. During post-ischemic reperfusion, activation of intracellular MMP-2 leads to cleavage of the contractile regulatory protein troponin-I. Conversely, myocardial stunning was attenuated by inhibition of MMP-2 activity [37,84-86].

In our study, low MMP-2 level was clearly observed in type $2 \mathrm{DM}$ and $\mathrm{DH}$ rats, which is consistent with the study of [85] who stated that MMP-2 is a good indicator for evaluating cardiac fibrosis in degenerative diseases like DM. The decreased MMP-2 significant level observed in our DC and DHC rat groups (II and III, respectively) when compared to group $\mathrm{C}$.

But, on the other hand, there was a significant increase in group $\mathrm{R}$ which was treated with rosiglitazone only and in group $\mathrm{R}+\mathrm{F}$ which was treated with rosiglitazone and felodipine combination in comparison to $\mathrm{DHC}$ rats group. Also, at the same time, there was no significant difference between groups $\mathrm{R}$ and $\mathrm{R}+\mathrm{F}$. This is supported by a positive correlation between BG and MMP-2. [87] is also consistent with this study.

It is obvious that, there is no significant difference between TGF- $\beta$ and MMP-2. 
In our study, the area percentage of masson trichrome stained CT fibers of treated groups were nearly the same as control healthy group that have excellent results than that of DHC group rats, which emphasize the great role of rosiglitazone and felodipine treatment in attenuating the cardiac fibrosis.

\section{Conclusion}

Our study revealed that DH rats develop hyperglycemia, hypertension and cardiac fibrosis. They also resulted in metabolic dyslipidemia, increased TNF- $\alpha$, TGF- $\beta$, collagen-I and collagen-III and decreased MMP-2. Our results demonstrate that treatment with rosiglitazone alone is able to improve the hyperglycemia, dyslipidemia, and to decrease TNF- $\alpha$, TGF- $\beta$, collagen-I and collagen-III and increased MMP-2 but within a minimal effect. Meanwhile, it had no effect on attenuating the hypertension which may lead to CADs again. Moreover, the combined treatment with rosiglitazone and felodipine is able to improve the hyperglycemia and has a great effect on attenuating the hypertension. The combined treatment is also able to improve dyslipidemia, and to decrease TNF- $\alpha$, TGF- $\beta$, collagen-I and collagenIII and increased MMP-2 but within a greater effect than treatment with rosiglitazone alone.

\section{Author details}

${ }^{1}$ Department of Biochemistry, Faculty of Pharmacy, Zagazig University, Zagazig, Egypt. 'Department of Biochemistry, Faculty of Pharmacy, October for Modern Science and Arts University (MSA), Egypt.

\section{Authors' contributions}

HEM put the idea of research and developed the study protocol, supervised samples and results interpretation and correlation assessments, and contributed to the revising of the manuscript. MEA participated in protocol writing, as well as experimental work, helped in statistical analysis, supervised samples' collection, preparation and analysis, provided superb scientific guidance regarding interpretation and presentation of results, and helped to draft the manuscript. MMH carried the designed protocol, performed the statistical analysis and contributed to the writing of the manuscript. All authors read and approved the final manuscript.

\section{Competing interests}

The authors declare that they have no competing interests.

Received: 13 November 2010 Accepted: 30 March 2011

Published: 30 March 2011

\section{References}

1. Creager MA, Lùscher TF: Diabetes and vascular disease: pathophysiology, clinical consequences, and medical therapy: part I. Circulation 2003, 108:1527-1532.

2. Hayat SA, Patel B, Khattar RS, Malik RA: Diabetic cardiomyopathy: mechanisms, diagnosis and treatment. Clin Sci 2004, 107:539-557.

3. Adeghate E: Molecular and cellular basis of the aetiology and management of diabetic cardiomyopathy: a short review. Mol Cell Biochem 2004, 261:187-191.

4. Fang ZY, Prins JB, Marwick TH: Diabetic cardiomyopathy: evidence, mechanisms, and therapeutic implications. Endocr Rev 2004, 25:543-567.

5. Gonzàlez-Vilchez F, Ayuela J, Ares M, Pi J, Castillo L, Martìn-Duràn R: Oxidative stress and fibrosis in incipient myocardial dysfunction in type 2 diabetic patients. Int J Cardiol 2005, 101:53-58.
6. Aronson D: Cross-linking of glycated collagen in the pathogenesis of arterial and myocardial stiffening of aging and diabetes. $J$ Hypertens 2003, 21:3-12.

7. From $\mathrm{AM}$, Scott CG, Chen $\mathrm{HH}$ : Changes in diastolic dysfunction in diabetes mellitus over time. Am J Cardiol 2009, 103:1463-1466.

8. Tenenbaum A, Motro M, Fisman EZ, Leor J, Boyko V, Mandelzweig L, Behar S: Status of glucose metabolism in patients with heart failure secondary to coronary artery disease. Am J Cardiol 2002, 90:529-532.

9. Takeshita F, Kodama M, Yamamoto H, Ikarashi $Y$, Ueda S, Teratani T, Yamamoto Y, Tamatani T, Kanegasaki S, Ochiya T, Quinn G: Streptozotocininduced partial beta cell depletion in nude mice without hyperglycaemia induces pancreatic morphogenesis in transplanted embryonic stem cells. Diabetologia 2006, 49:2948-2958.

10. Rizzo G, Fiorucci S: PPARs and other nuclear receptors in inflammation. Curr Opin Pharmacol 2006, 6(4):421-427.

11. Ikebukuro $K$, Adachi $Y$, Yamada $Y$, Fujimoto $S$, Seino $Y$, Oyaizu H: Treatment of Streptozotocin-induced diabetes mellitus by transplantation of islet cells Plus bone Marrow cells via portal vein in rats. Transplantation 2002, 73:512-518.

12. YU S, Reddy JK: "Transcription coactivators for peroxisome proliferatoractivated receptors". Biochim. Biophys. Acta 2007, 1771(8):936-51.

13. BISHOP-BAILEY D: Peroxisome proliferator-activated receptors in the cardiovascular system. Br J Pharmacol 2000, 129:823-834.

14. Collin M, Thiemermann C: The PPAR-gamma ligand 15-deoxy (Delta12,14) prostaglandin $\mathrm{J}(2)$ reduces the liver injury in endotoxic shock. Eur $\mathrm{J}$ Pharmacol 2003, 476:257-258.

15. Cuzzocrea S, Pisano B, Dugo L, lanaro A, Patel NS, Paola RD, Genovese T, Chatterjee PK, Rosa MD, Caputi AP, Thiemermann C: Rosiglitazone and 15deoxy-\{Delta\}12,14-prostaglandin $\mathrm{J} 2$, ligands of the peroxisome proliferator-activat. Br J Pharmacol 2003, 140:366-376.

16. Gilde AJ, Van Bilsen M: Peroxisome proliferator-activated receptors (PPARS): regulators of gene expression in heart and skeletal muscle. Acta Physiol Scand 2003, 178:425-434.

17. Khandoudi N, Delerive P, Berrebi-Bertrand I, Buckingham RE, Staels B, Bril A: Rosiglitazone, a peroxisome proliferator-activated receptor- $\gamma$, inhibits the jun $\mathrm{NH}$-terminal kinase/activating protein 1 pathway and protects the heart from ischemia/reperfusion injury. Diabetes 2002 , 51:1507-1514.

18. Sidell RJ, Cole MA, Draper NJ, Desrois M, Buckingham RE, Clarke K: Thiazolidinedione treatment normalizes insulin resistance and ischemic injury in the Zucker fatty rat heart. Diabetes 2002, 51:1110-1117.

19. Takano H, Nagai T, Asakawa M, Toyozaki T, Oka T, Komuro I, Saito T, Masuda Y: Peroxisome proliferator-activated receptor activators inhibit lipopolysaccharide-induced tumor necrosis factor-a expression in neonatal rat myocytes. Circ Res 2000, 87:596-602.

20. Yuan Z, Liu Y, Liu Y, Zhang J, Kishimoto C, Wang Y, Ma A, Liu Z: Peroxisome proliferation-activated receptor-gamma ligands ameliorate experimental autoimmune myocarditis. Cardiovasc Res 2003, 59:685-694.

21. Shiomi T, Tsutsui H, Hayashidani S, Suematsu N, Ikeuchi M, Wen J, Ishibashi M, Kubota T, Egashira K, Takeshita A: Pioglitazone, a peroxisome proliferator-activated receptor-gamma agonist, attenuates left ventricular remodeling and failure after experimental myocardial infarction. Circulation 2002, 106:3126-3132.

22. Wayman NS, Hattori Y, McDonald MC, Mota-Filipe H, Cuzzocrea S, Pisano B, Chatterjee PK, Thiemermann C: Ligands of the peroxisome proliferatoractivated receptors (PPAR- $\gamma$ and PPAR- $a$ ) reduce myocardial infarct size. FASEB J 2002, 16:1027-1040.

23. Yue T, Chen J, Bao W, Narayan PK, Bril A, Jiang W, Lysko PG, Gu J-L, Boyce R, Zimmerman DM, Hart TK, Buckingham RE, Ohlstein EH: In vivo myocardial protection from ischemia/reperfusion injury by the peroxisome proliferatoractivated receptor- $\gamma$ agonist rosiglitazone. Circulation 2001, 104:2588-2594

24. Meigs JB: Invited commentary: insulin resistance syndrome? Syndrome $\mathrm{X}$ ? Multiple metabolic syndrome? A syndrome at all? Factor analysis reveals patterns in the fabric of correlated metabolic risk factors. Am J Epidemiol 2000, 152:908-12.

25. Sakkinen PA, Wahl P, Cushman M, Lewis MR, Tracy RP: Clustering of procoagulation, inflammation, and fibrinolysis variables with metabolic factors in insulin resistance syndrome. Am J Epidemio/ 2000, 152:897-907.

26. Bonora $E$, et al: Carotid atherosclerosis and coronary heart disease in the metabolic syndrome: prospective data from the Bruneck study. Diabetes Care 2003, 26:1251-7. 
27. Reilly MP, et al: Measures of insulin resistance add incremental value to the clinical diagnosis of metabolic syndrome in association with coronary atherosclerosis. Circulation 2004, 110:803-9.

28. Iwasaki Y, Asai M, Yoshida M, Nigawara T, Kambayashi M, Oiso Y, Nakashima N: Nilvadipine inhibits nuclear factor-kappaB-dependent transcription in hepatic cells. Clin Chim Acta 2004, 350:151-157.

29. Chen YG, Xu F, Zhang Y, Ji QS, Sun Y, Lü RJ, et al: Effect of aspirin plus clopidogrel on inflammatory markers in patients with non-ST-segment elevation acute coronary syndrome. Chin Med J 2006, 119:32-36.

30. Sun M, Dawood F, Wen WH, Chen M, Dixon I, Kirshenbaum LA, et al: Excessive tumor necrosis factor activation after infarction contributes to susceptibility of myocardial rupture and left ventricular dysfunction. Circulation 2004, 110:3221-3228.

31. Valgimigli M, Ceconi C, Malagutti $P$, Merli E, Soukhomovskaia O, Francolini G, et al: Tumor necrosis factor-alpha receptor 1 is a major predictor of mortality and new-onset heart failure in patients with acute myocardial infarction: the Cytokine-Activation and Long-Term Prognosis in Myocardial Infarction (C-ALPHA) study. Circulation 2005, 111:863-870.

32. Wada H, Saito K, Kanda T, Kobayashi I, Fujii H, Fujigaki S, et al: Tumor necrosis factor-a plays a role in actual viral myocarditis in mice. Circulation 2001, 103:743-749.

33. Li W, Gan R, Sun G: Chronic treatment of enbrel in rats with isoproterenol-induced congestive heart failure limits left ventricular dysfunction and remodeling. Chin Med J 2002, 115:1166-1169.

34. Mann DL, McMurray JJ, Packer M, Swedberg K, Borer JS, Colucci WS, et al: Targeted anticytokine therapy in patients with chronic heart failur: results of the randomized etanercept worldwide evaluation (RENEWAL). Circulation 2004, 109:1594-1602.

35. McKarns SC, Schwartz RH: Distinct effects of TGF-beta 1 on CD4+ and CD8+ T cell survival, division, and IL-2 production: a role for $T$ cell intrinsic Smad3. J Immunol 2005, 174:2071-2083.

36. Cheung PY, Sawicki G, Wozniak M, Wang W, Radomski MW, Schulz R: Matrix metalloproteinase-2 contributes to ischemia- reperfusion injury in the heart. Circulation 2000, 101:1833-9.

37. Lalu MM, Pasini E, Schulze CJ, Ferrari-Vivaldi M, Ferrari-Vivaldi G, Bachetti T, et al: Ischaemia-reperfusion injury activates matrix metalloproteinases in the human heart. Eur Heart J 2005, 26:27-35.

38. Mujumdar VS, Smiley LM, Tyagi SC: Activation of matrix metalloproteinase dilates and decreases cardiac tensile strength. Int J Cardiol 2001, 79:277-86.

39. Jugdutt Bl: Ventricular remodeling after infarction and the extracellular collagen matrix: when is enough enough? Circulation 2003, 108:1395-1403.

40. Xing S, Tan H, Bi X, Zhong M, Zhang Y, Zhang W: Felodipine Reduces Cardiac Expression of IL-18 and Perivascular Fibrosis in Fructose-Fed Rats. Mol Med 2008, 14(7-8):395-402.

41. Zhang M, Lv XY, Li J, Xu ZG, Chen L: The characterization of high-fat diet and multiple low-dose streptozotocin induced type 2 diabetes rat model. Exp Diabetes Res 2008, 704045.

42. Waynforth $H B$, Flecknell PA: Experimental and surgical technique in the rat. Academic Press London; 2 1998, 66-113.

43. Melin J, Hellberg O, Akyurek LM, Kallskog O, Larsson E, Fellstrom B: Ischemia causes rapidly progressive nephropathy in the diabetic rat. Kidney Int 1997, 52:985-991.

44. Johns DG, Ao Z, Eybye M, Olzinski A, Costell M, Gruver S, Smith SA, Douglas SA, Macphee $\mathrm{CH}$ : Rosiglitazone protects against ischemia/ reperfusion- induced leukocyte adhesion in the zucker diabetic fatty rat. J Pharmacol Exp Ther 2005, 315:1020-1027.

45. Xing S, Tan H, Bi X, Zhong M, Zhang Y, Zhang W: Felodipine Reduces Cardiac Expression of IL-18 and Perivascular Fibrosis in Fructose-Fed Rats. Mol Med 2008, 14(7-8):395-402.

46. Basile DP, Martin DR, Hammerman MR: Extracellular matrix-related genes in kidney after ischemic injury: potential role for TGF- $\beta$ in repair. Am J Physiol Renal Physiol 1998, 275:F894-F903.

47. Drury RA, Wallington EA: Histological techniques. Oxford University press. Oxford, N.Y., Toronto; 5 1980, 27-29.

48. Bancroft J, Stevens A: Theory and Practice of Histological Techniques., 2 1982, 131-135.

49. Braham D, Trinder P: An improved colour reagent for the determination of blood glucose by the oxidase system. Analyst 1972, 97:142-145.

50. Nagele U, Hagele EO, Sauer G, Wiedemann E, Lehmann P, Wahlefeld WA, Gruber W: Reagent for the enzymatic determination of serum triglycerides with improved lipolytic efficiency. J Clin Chem Clin Bio 1984, 22:165-174.

51. Fascse CF: Enzymatic colorimetric method determination of total cholesterol in human serum. Clin Chem 1982, 28:901-907.

52. Warnick GR, Benderson JM, Albers JJ: Dextran sulphate-Mg2+ precipitation procedure or quantification of high density lipoprotein cholesterol. Clin Chem 1982, 28(6):1379-1388.

53. Friedewald WT, Levy RI, Fredrickson DS: Estimation of the concentration of low density lipoprotein cholesterol in plasma without use of preparative ultracentrifuge. Clin Chem 1972, 18(6):499-502.

54. Bonavida B: Immunomodulatory effect of tumor necrosis factor. Biotherapy 1991, 3:127-33.

55. Nathan DM, Davidson MB, DeFronzo RA, Heine RJ, Henry RR, Pratley R, Zinman B: Impaired Fasting Glucose and Impaired Glucose Tolerance; Implications for care. Diabetes Care 2007, 30(3):753-759.

56. Yanagawa T, Taniguchi A, Fukushima M, Nakai Y, Nagasaka S, Ohgushi M, Matsumoto K, Kuroe A, Ohya M, Seino Y: Leptin, triglycerides, and interleukin 6 are independently associated with C-reactive protein in Japanese type 2 diabetic patients. Diabetes Research and Clinical Practice 2007, 75:2-6.

57. Trichon B, Roe M: Diabetes mellitus and ischemic heart disease. Diabetes and cardiovascular disease: Integrating science and clinical medicine Marso PS, Stern MD Lippincott Williams and Wilkins; 2004, 241-250.

58. Cefalu WT: Insulin resistance: cellular and clinical concepts. Exp Biol Med 2001, 226:13-26

59. Ares-Carrasco S, Picatoste B, Benito-Martín A, Zubiri I, Sanz AB, SánchezNiño MD, Ortiz A, Egido J, Tuñón J, Lorenzo O: Myocardial fibrosis and apoptosis, but not inflammation, are present in long-term experimental diabetes. Am J Physiol Heart Circ Physiol 2009, 297 H2109-H2119.

60. Akbarzadeh A, Norouzian D, Mehrabi MR, Jamshidi Sh, Farhangi A, Allah Verdi A, Mofidian SMA, Lame Rad B: Induction of diabetes by streptozotocin in rats. Indian Journal of Clinical Biochemistry 2007, 22(2):60-64.

61. El-Batran SA, Abdel-Salam OM, Nofal SM, Baiuomy AR: Effect of rosiglitazone and nateglinide on serum glucose and lipid profile alone or in combination with the biguanide metformin in diabetic rats. Pharmacol Res 2006, 53:69-74.

62. Qian Y, Li S, Ye S, Chen Y, Zhai Z, Chen K, Yang G: Renoprotective effect of rosiglitazone through the suppression of renal intercellular adhesion molecule-1 expression in streptozotocin-induced diabetic rats. J Endocrinol Invest 2008, 31:1069-1074.

63. Abu-Abeeleh M, Bani Ismail Z, Alzaben KR, Abu-Halaweh SA, Al Essa MK, Abu-Abeeleh J, Alsmady MM: Induction of diabetes mellitus in rats using intraperitoneal streptozotocin: a comparison between 2 strains of rats. Eur J Nephrol 2009, 24:46-53.

64. Grossman E, Messerli FH: Cardiovascular Diabetology: Clinical, Metabolic and Inflammatory Facets. Adv Cardiol Basel, Karger 2008, 45:82-106.

65. Wilson PW, D'Agostino RB, Sullivan L, Parise H, Kannel WB: Overweight and obesity as determinants of cardiovascular risk: the Framingham experience. Arch Intern Med 2002, 162:1867-1872.

66. Snow V, Hornbake R, Mottur-Pilson C, Weiss KB: Lipid control in the management of type 2 diabetes mellitus: a clinical practice guideline from the American College of Physicians. Ann Intern Med 2004, 140:644-649.

67. American Diabetes Association: Treatment of Hypertension in Adults with Diabetes. Diabetes Care 2003, 26(suppl 1):s80-s82.

68. Aronson D: Cross-linking of glycated collagen in the pathogenesis of arterial and myocardial stiffening of aging and diabetes. $J$ Hypertens 2003, 21:3-12.

69. Asbun J, Villarreal FJ: The Pathogenesis of Myocardial Fibrosis in the Setting of Diabetic Cardiomyopathy. J Am Coll Cardiol 2006, 47:693-700.

70. Shiomi T, Tsutsui $H$, Ikeuchi $M$ et al: Streptozotocin-induced hyperglycemia exacerbates left ventricular remodeling and failure after experimental myocardial infarction. J Am Coll Cardiol 2003, 42:165-172.

71. Backlund T, Palojoki E, Saraste A, et al: Sustained cardiomyocyte apoptosis and left ventricular remodelling after myocardial infarction in experimental diabetes. Diabetologia 2004, 47:325-330.

72. Opara EC: Oxidative stress, micronutrients, diabetes mellitus and its complications. The Journal of Royal Society for the Promotion of Health 2002, 122(1):28-34 
73. Waller DG, Renwick AG, Hillier K: Ischemic Heart Disease. In Medical Pharmacology and Therapeutics. Volume Chapter 5. W.B.Saunders; Spain; 2001:81.

74. Nand W, Sowers JR: Epidemiology of diabetes. J Clin Pharmacol 2004, 44:397-405.

75. Waller DG, Renwick AG, Hillier K: Ischemic Heart Disease. In Medical Pharmacology and Therapeutics. Volume Chapter 5. WB Saunders; Spain; 2001:81.

76. Opie LH: Clinician Update; Metabolic Syndrome. Circulation 2007, 115 : e32-e35.

77. Sampson M, Davies I, Gavrilovic J, Sussams B, Brown J, Astley S, Hughes DA Plasma matrix metalloproteinases, low density lipoprotein oxidisability and soluble adhesion molecules after a glucose load in Type 2 diabetes. Cardiovasc Diabetol 2004, 3(1):7.

78. Gao X, Picchi A, Zhang C: Upregulation of TNF-alpha and Receptors Contribute to Endothelial Dysfunction in Zucker Diabetic Rats. Am J Biomed Sci 2010, 2(1):1-12.

79. Dinh W, Füth R, Nickl W, Krahn T, Ellinghaus P, Scheffold T, Bansemir L, Bufe A, Barroso MC, Lankisch M: Elevated plasma levels of TNF-alpha and Interleukin-6 in patients with diastolic dysfunction and glucose metabolism disorders. Cardiovascular Diabetology 2009, 8:58.

80. Mizushige K, Yao L, Noma T, Kiyomoto H, Yu Y, Hosomi N, Ohmori K, Matsuo H: Alteration in left ventricular diastolic filling and accumulation of myocardial collagen at insulin-resistant prediabetic stage of a type II diabetic rat model. Circulation 2000, 101:899-907.

81. Shigeyama J, Yasumura Y, Sakamoto A, Ishida Y, Fukutomi T, Itoh M, Miyatake K, Kitakaze M: Increased gene expression of collagen Types I and III is inhibited by ß-receptor blockade in patients with dilated cardiomyopathy. European Heart Journal 2005, 26(24):2698-2705.

82. Filippi CM, Juedes AE, Oldham JE, Ling E, Togher L, Peng $Y$, Flavell RA, von Herrath MG: Transforming Growth Factor- $\beta$ Suppresses the Activation of CD8+ T-Cells When Naïve but Promotes Their Survival and Function Once Antigen Experienced. Diabetes 2008, 57(10):2684-2692.

83. Lijnen PJ, Petrov W, Fagard RH: Induction of cardiac fibrosis by transforming growth factor-beta (1). Mol Genet Metab 2000, 71:418-435.

84. Martinez A, Oh HR, Unsworth EJ, Bregonzio C, Saavedra JM, StetlerStevenson WG, et al: Matrix metalloproteinase-2 cleavage of adrenomedullin produces a vasoconstrictor out of a vasodilator. Biochem J 2004, 383:413-8.

85. Tsuruda T, Costello-Boerrigter LC, Burnett LC Jr: Matrix metalloproteinases: pathways of induction by bioactive molecules. Heart Fail Rev 2004, 9:53-61.

86. Lindsey ML: Matrix metalloproteinase induction and inhibition in myocardial infarction. Heart Failure Rev 2004, 9:7-19.

87. Wang W, Schulze CJ, Suarez-Pinzon WL, Dyck JR, Sawicki G, Schulz R: Intracellular action of matrix metalloproteinase-2 accounts for acute myocardial ischemia and reperfusion injury. Circulation 2002, 106:1543-9.

doi:10.1186/1758-5996-3-4

Cite this article as: Mohamad et al: Management of cardiac fibrosis in diabetic rats; the role of peroxisome proliferator activated receptor gamma (PPAR-gamma) and calcium channel blockers (CCBs).

Diabetology \& Metabolic Syndrome 2011 3:4.

\section{Submit your next manuscript to BioMed Central and take full advantage of:}

- Convenient online submission

- Thorough peer review

- No space constraints or color figure charges

- Immediate publication on acceptance

- Inclusion in PubMed, CAS, Scopus and Google Scholar

- Research which is freely available for redistribution

Submit your manuscript at www.biomedcentral.com/submit
Biomed Central 